\title{
Effectiveness of different root canal imigation protocols in treatment of immature permanent teeth
}

\author{
Krasimir Hristov ${ }^{1}$, Nataliya Gateva ${ }^{2}$
}

1. Assistant professor, Department of Pediatric Dentistry, Faculty of Dental Medicine, Medical University - Sofia;

2. Associate professor, Department of Pediatric Dentistry, Faculty of Dental Medicine, Medical University - Sofia

\begin{abstract}
Introduction: The aim of this study was to determine the efficiency of 6 irrigation protocols in eliminating bacteria in root canals of immature permanent teeth.

Materials and methods: Root segments of $10 \mathrm{~mm}$ were created form immature permanent teeth. The segments were inoculated with Enterococcus faecalis for 2 weeks. Canals were disinfected by 1) passive ultrasonic irrigation; 2)continuous irrigation with sodium hypochlorite and EDTA; 3) XP-Endo finisher, sodium hypochlorite and EDTA; 4) XP-Endo finisher, sodium hypochlorite and citric acid; 5) Gentlefile brush, sodium hypochlorite and EDTA; 6) Gentlefile brush, sodium hypochlorite and citric acid.

Dentinal chips were collected from the canals. Colony forming units were counted, and the effectiveness of each disinfection protocol was reported in terms of log10 bacterial growth reduction.

Results: The number of microorganisms in the ultrasound-activated samples was reduced the least, followed by those prepared according to the American Association of Endodontic Protocol, and segments prepared with Gentlefile and EDTA. The reduction in the number of colony forming units is most
\end{abstract}


significant in the samples treated with XP-Endo Finisher and EDTA, with XP-Endo Finisher and citric acid, and Gentlefile and citric acid, with no statistically significant difference between the three groups $(p>0.05)$.

Conclusions: By supplementing the irrigation protocol with minimal mechanical instrumentation, a more efficient reduction of the microflora is achieved in immature permanent teeth.

Keywords: immature permanent teeth, irrigation protocol, citric acid

\section{Introduction}

Immature permanent teeth with pulp necrosis are challenging for treatment due to the importance of bacteria and debris elimination without removal of root dentin. Endodontic treatment of such teeth is similar to the treatment of a very wide and oval root canal - a problem considered in modern endodontics (1).

Mechanical instrumentation of oval root canals with hand and rotary files has been shown to leave untreated surfaces (2-6). This spaces may contain residual pulp or bacterial biofilm in infected root canals that may affect adversely the treatment outcome (7).

Most of the microorganisms are in the main canal or in planktonic form. The main canal has many branches - lateral canals, isthmuses, anastomoses, niches, all of which are interconnected (8). Irrigation and disinfectants are effective against microorganisms in a planktonic form, but their effectiveness is reduced against microorganisms in biofilms or invading lateral canals or irregularities. In order for the irrigants to be effective enough in these cases, the biofilm must be removed mechanically (8).

\section{Aim}

The aim of this study is to evaluate and compare the ability of six different irrigation protocols to remove microorganisms from the root canal of immature permanent teeth.

\section{Material and methods}

The study was performed on 70 immature permanent teeth extracted for the purpose of orthodontic treatment from healthy children between the age of 12 to 17 . The teeth were included in the study after the parents signed informed consent for their use. The roots were prepared as follows: the coronary part of the tooth was removed with a diamond separator (Superflex, Edenta, Switzerland) and a root segment of 10 $\mathrm{mm}$ was created. This was done to minimize variations in the root canal anatomy in order to achieve a real comparability between the results for colony forming units (CFUs). The pulp tissue was removed from the root canal using a barbed broach (VDW, München, Germany). 
Samples were apically sealed with light-curing resin composite (Admira, VOCO, Cuxhaven, Germany) and sequential irrigation was carried out with $5 \mathrm{ml} 2.5 \% \mathrm{NaOCl}, 5 \mathrm{ml} \mathrm{17 \%} \mathrm{EDTA,} 5 \mathrm{ml} 2.5 \% \mathrm{NaOCl}$ to remove the smear layer. The roots were then placed for 48 hours in distilled water. The samples were autoclaved at $121^{\circ} \mathrm{C}$ for $20 \mathrm{~min}$ and stored in sterile phosphate buffer at $4^{\circ} \mathrm{C}$ until used. Prior to inoculation of the segments with bacterial suspension, the phosphate buffer solution was aspirated under sterile conditions.

The root segments were immersed in brain-heart infusion broth inoculated with Enterococcus faecalis. Two segments were immersed in sterile control medium to confirm that no contamination of the samples occurred during the experiment. Samples were incubated for 14 days at $37^{\circ} \mathrm{C}$ and $5 \% \mathrm{CO}$. The culture medium was changed every two days.

When a dense biofilm was confirmed by scanning electron microscopy, the infected 70 root segments were randomly divided into 7 groups of 10 samples in each group. An endodontic needle with a lateral opening (Endo Top Irrigation Needles, Cerekamed, Poland) was used to deliver the irrigation, adjusted to working length of $9 \mathrm{~mm}$. The 7 groups were as follows:

- First group - irrigation with phosphate buffer solution to determine the initial number of microorganisms;

- Second group - passive ultrasonic irrigation - $5 \mathrm{ml} 1.5 \%$ hypochlorite for $20 \mathrm{~s}$, three cycles; $17 \%$ EDTA 1 min. A wireless ultrasonic handpiece (Ultra X, Eighteeth, Changzhou Sifary Technology Co., China) with an activation tip (X Silver, Eighteeth, Changzhou Sifary Technology Co, Chi) is used;

- Third group - continuous irrigation with $20 \mathrm{ml}$ of $1.5 \%$ hypochlorite for $5 \mathrm{~min}$, followed by $20 \mathrm{ml}$ of 17\% EDTA for $5 \mathrm{~min}$, recommended by the American Association of Endodontics;

- Fourth group - instrumentation with XP-Endo finisher - $5 \mathrm{ml} 1.5 \%$ hypochlorite for $60 \mathrm{~s}$, three cycles of $20 \mathrm{~s}$, at $800 \mathrm{rpm}$ and torque of $1 \mathrm{~N} / \mathrm{cm}, 17 \%$ EDTA $1 \mathrm{~min}$ - three cycles of $20 \mathrm{~s}$;

- Fifth group - instrumentation with XP-Endo finisher - $5 \mathrm{ml} 1.5 \%$ hypochlorite for $60 \mathrm{~s}$, three cycles of $20 \mathrm{~s}$, at $800 \mathrm{rpm}$ and torque of $1 \mathrm{~N} / \mathrm{cm}, 10 \%$ citric acid for $1 \mathrm{~min}$ - three cycles of $20 \mathrm{~s}$;

- Sixth group - instrumentation with Gentlefile brush - $5 \mathrm{ml} 1.5 \%$ hypochlorite for $60 \mathrm{~s}$, three cycles of $20 \mathrm{~s}, 17 \%$ EDTA $1 \mathrm{~min}$ - three cycles of $20 \mathrm{~s}$ with the commercially available handpiece.

- Seventh group - Gentlefile brush - $5 \mathrm{ml} 1.5 \%$ hypochlorite for $60 \mathrm{~s}$, three cycles of $20 \mathrm{~s}, 10 \%$ citric acid for $1 \mathrm{~min}$ - three cycles of $20 \mathrm{~s}$ with the commercially available handpiece. 
After irrigation, each canal was rinsed with $5 \mathrm{ml}$ of saline. The root wall was brushed with a No. 3 Peeso reamer and the dentinal chips were transferred to a sterile eppendorf tube with added brain-heart infusion broth. Three sterile paper points were used to absorb residual fluid from the root canal. They were placed in the same tube. The cultures were incubated in blood agar at $37^{\circ} \mathrm{C}$ and $5 \% \mathrm{CO} 2$ using the streak culture method. After 24 hours, CFUs were counted, and the mean CFU counts were calculated. The effectiveness of each disinfection protocol was reported in terms of log10 bacterial growth reduction. The data were analyzed using software SPSS ver. 19. To identify any significant differences between the groups Tukey multiple comparison test was performed.

\section{Results}

The mean values of the colony forming units of the remaining microbial organisms after treatment with the respective irrigation protocols were determined for each group (Table 1, Diagram 1). No microorganisms were isolated from the sterile control groups.

Table 1. Bacterial growth in each experimental group. SD standard deviation

\begin{tabular}{|l|l|l|l|l|l|l|l|}
\hline & PBS & Ultrasound & AAE & XP-Endo & $\begin{array}{l}\text { XP-Endo- } \\
\text { CA }\end{array}$ & Gentlefile & Gentlefile-CA \\
\hline Mean value & 6,09247 & 4,43167 & 3,45105 & 2,78061 & 1,98061 & 3,09187 & 1,87604 \\
\hline SD & 0,32031 & 0,12229 & 0,1548 & 1,50215 & 1,05729 & 1,64652 & 1,01147 \\
\hline Min & 5,90308 & 4,30102 & 3,30102 & 0,00 & 0,00 & 0,00 & 0,00 \\
\hline Max & 6,69897 & 4,60205 & 3,69897 & 3,90308 & 2,69897 & 4,17609 & 2,60205 \\
\hline
\end{tabular}

In order to evaluate the effectiveness of each of the protocols applied, a comparative evaluation of the mean bacterial residuals between the groups was performed using the Tukey test (Table 2). 
Table 2. Differences between groups according to mean values of residual bacteria (Log10 (CFU/ml), Post Hoc Tukey HSD Analysis).

\begin{tabular}{|c|c|c|c|c|c|}
\hline \multicolumn{6}{|l|}{\begin{tabular}{|l|} 
Tukey HSD \\
\end{tabular}} \\
\hline \multirow[b]{2}{*}{ Group A } & \multirow[b]{2}{*}{ Group B } & \multirow[t]{2}{*}{\begin{tabular}{|l} 
Difference in \\
mean value (A- \\
B)
\end{tabular}} & \multirow[t]{2}{*}{$\mathrm{p}$} & \multicolumn{2}{|c|}{ 95\% Confidence interval } \\
\hline & & & & Lower limit & Upper limit \\
\hline \multirow[t]{6}{*}{ PBS } & Ultrasound & 1.660799755 & 0.009185 & 0.274654441 & 3.046945069 \\
\hline & AAE & 2.641417752 & 0.000005 & 1.255272438 & 4.027563066 \\
\hline & XP-Endo & 3.311854256 & 0.000000 & 1.925708942 & 4.69799957 \\
\hline & XP-Endo-CA & 4.111854256 & 0.000000 & 2.725708942 & 5.49799957 \\
\hline & Gelntlefile & 3.000593756 & 0.000000 & 1.614448442 & 4.38673907 \\
\hline & Gentlefile-CA & 4.216430005 & 0.000000 & 2.830284691 & 5.602575319 \\
\hline \multirow{5}{*}{ Ultrasound } & AAE & 0.980617997 & 0.334705 & -0.40552732 & 2.366763311 \\
\hline & XP-Endo & 1.651054501 & 0.009798 & 0.264909187 & 3.037199815 \\
\hline & XP-Endo-CA & 2.451054501 & 0.000023 & 1.064909187 & 3.837199815 \\
\hline & Gelntlefile & 1.339794001 & 0.064673 & -0.04635131 & 2.725939315 \\
\hline & Gentlefile-CA & 2.55563025 & 0.000010 & 1.169484936 & 3.941775564 \\
\hline \multirow[t]{4}{*}{ AAE } & XP-Endo & 0.670436504 & 0.759395 & -0.71570881 & 2.056581818 \\
\hline & XP-Endo-CA & 1.470436504 & 0.030616 & 0.08429119 & 2.856581818 \\
\hline & Gelntlefile & 0.359176004 & 0.985223 & \begin{tabular}{|l|}
-1.02696931 \\
\end{tabular} & 1.745321318 \\
\hline & Gentlefile-CA & 1.575012253 & 0.016048 & 0.188866939 & 2.961157567 \\
\hline \multirow[t]{3}{*}{ XP-Endo } & XP-Endo-CA & 0.8 & 0.580793 & -0.58614531 & 2.186145314 \\
\hline & Gelntlefile & -0.3112605 & 0.993058 & -1.69740581 & 1.074884814 \\
\hline & Gentlefile-CA & 0.904575749 & 0.432673 & -0.48156957 & 2.290721063 \\
\hline \multirow[t]{2}{*}{ XP-Endo-CA } & Gelntlefile & -1.1112605 & 0.198980 & -2.49740581 & 0.274884814 \\
\hline & Gentlefile-CA & 0.104575749 & 0.999987 & -1.28156957 & 1.490721063 \\
\hline Gelntlefile & Gentlefile-CA & 1.215836249 & 0.122788 & -0.17030906 & 2.601981563 \\
\hline
\end{tabular}




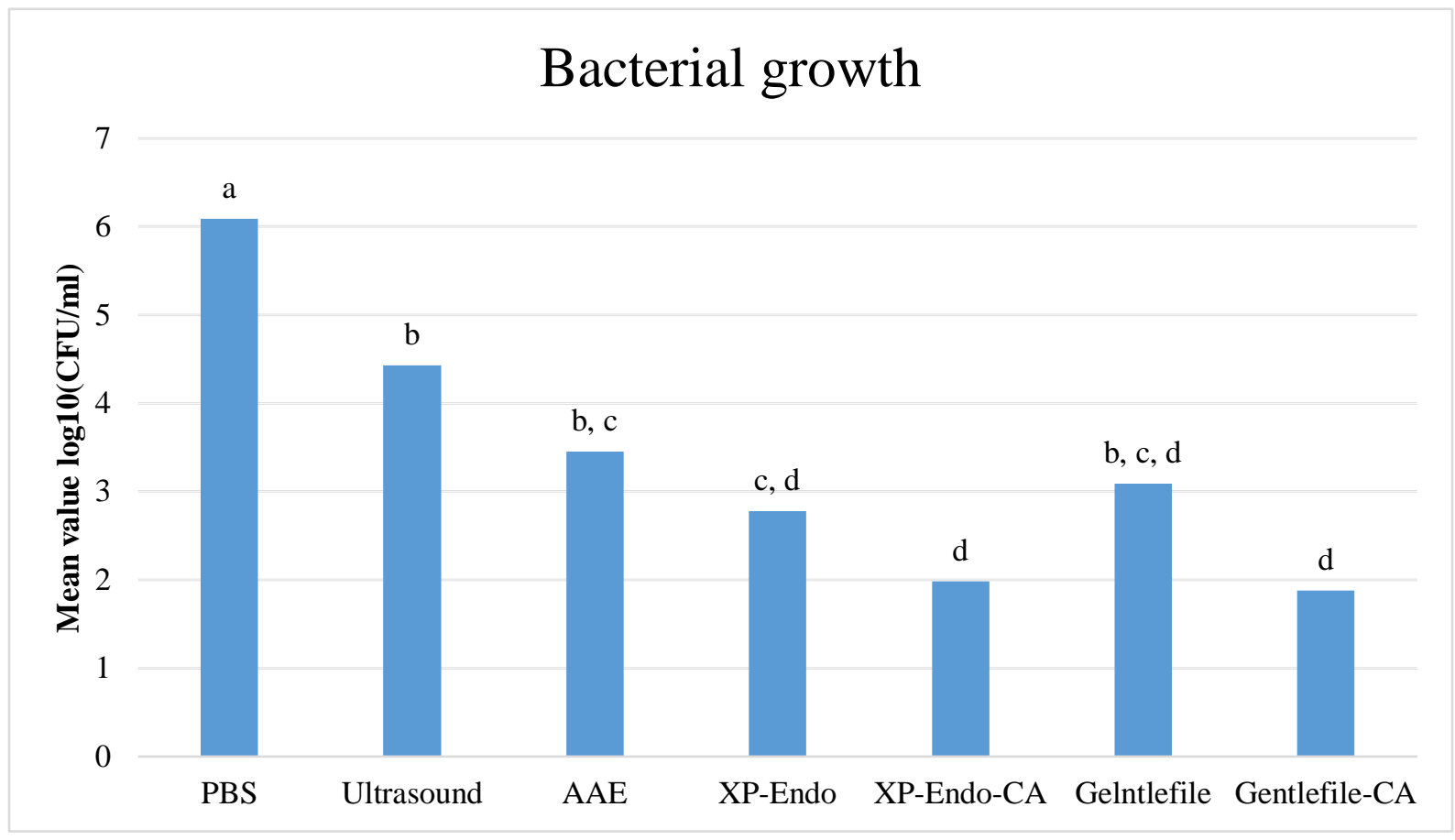

Figure 1. Bacterial growth in each experimental group. The different letters indicate a statistically significant difference between the groups $(p<0.05)$.

The statistical analysis revealed that the average number of colony forming units in each group was significantly lower than the phosphate buffered segments (group 1, p <0.05). In the other groups, the number of microorganisms in the ultrasound-activated samples (group 2) was reduced the least, followed by those prepared according to the recommendation of the American Association of Endodontic Protocol (group 3) and segments prepared with Gentlefile and irrigated with EDTA (group 6).

The results suggest that the obtained antibacterial effect is due to the disinfectant properties of the irrigants, rather than to their rinsing action. This is confirmed by the statistically significant difference in the mean number of microorganisms in group 1 treated with phosphate buffer solution and the other groups.

The reduction in the number of CFUs is most significant in the samples treated with XP-Endo Finisher with EDTA (group 4), with XP-Endo Finisher and citric acid (group 5) and the samples treated with Gentlefile and citric acid (group 7), with no statistically significant difference between the three groups ( $>0.05$ ). The data show that minimal mechanical instrumentation of the root canal with appropriate files significantly improves the removal of bacteria from the dentin surface with a shorter treatment protocol. 


\section{Discussion}

Effective removal of bacterial biofilm contributes to the success of regenerative endodontics (9). It is known that root canal infection is always polymicrobial (10). In our study, we used a monomicrobial biofilm model to avoid all possible variations caused by interspecies interactions (11). E. faecalis was selected as the test species because these bacteria have the ability to form biofilms, survive under severe conditions and counteract the antimicrobial effect of calcium hydroxide (11). Moreover, E. faecalis is often isolated from the root canal in failed endodontic treatments $(12,13)$.

In all protocols, we used $1.5 \% \mathrm{NaOCl}$ instead of $2.5 \% \mathrm{NaOCl}$, as it is known that high sodium hypochlorite concentration impairs stem cell attachment to the dentin surface (14), may prevent odontoblast differentiation mediated by growth factors since it denatures these factors (15) and it is toxic to the stem cells from apical papilla (16). Decreasing the concentration of the solution leads to a decrease in its toxicity, but also in the antibacterial effect and the ability to dissolve tissues (17). Concentrations of $1.5 \% \mathrm{NaOCl}$ are recommended for the purpose of regenerative endodontics by AAE (18), and concentrations of $2.5 \% \mathrm{NaOCl}$ are preferred by the European Society of Endodontics (19). Traditional endodontic disinfectants only limit the infection (16). To use their full capacity, these solutions must be activated. Our study examined the effect of different methods of activating irrigation solutions on immature permanent teeth with pulp necrosis. Only one of the protocols (group 3) does not use tools for activating the solutions, while the others use passive ultrasonic irrigation (group 2), the innovative XP-endo Finisher system (groups 4 and 5) and Gentlefile system (Groups 6 and 7). The number of microorganisms in ultrasound-activated samples was reduced the least, followed by those prepared according to the protocol recommended by the American Association of Endodontists (group 3). In fact, the AAE protocol relies on longer irrigation time and more hypochlorite and EDTA to cope with the infection. Theoretically, the effect of passive ultrasonic irrigation is inversely proportional to the thickness of the microbial biofilm and the width of the root canal (20). Immature permanent teeth have wide oval canals, and this explains the insufficient effect of passive ultrasonic irrigation on their disinfection. Our results confirm this.

There is little data in the specialized literature on the use of citric acid, especially in permanent immature teeth. Exogenous citrate added to the culture medium or released from the biomaterial during its absorption is known to increase alkaline phosphatase gene expression and osteoblastic phenotypic progression both in vitro and in vivo (21).

Promising results have been published on the effect of citric acid on the vitality of fibroblasts and macrophages (22-24) and on its use as an irrigant in the endodontic protocol for permanent teeth (25). In the same time citric acid has weaker proinflammatory action compared to EDTA-based solutions and it plays important natural role in the tricarboxylic acid cycle, thus regulating energy homeostasis and cellular metabolism $(26,27)$.

In two of the protocols, we used citric acid to find out if it would increase the effectiveness of the applied irrigation protocol. Citric acid has similar to EDTA effect. The use of $10 \%$ citric acid in combination with $2.5 \%$ $\mathrm{NaOCl}$ is known to be a good approach for removing the smear layer from the root canal dentin and opening the dentin tubules. Its efficacy does not differ from that of 17\% EDTA (25). In the same time citric acid is well tolerated by the stem cells from apical papilla, i.e. it is not more toxic than EDTA for the apical papilla, which is important for immature permanent teeth with pulp necrosis. Our results indicated that the use of citric acid in the irrigation protocol (groups 5 and 7) significantly improves its antibacterial effectiveness in 
immature permanent teeth, compared to other groups in which it is not included in the irrigation protocol (Table 2). There are no published previous research on the effects of citric acid as a part of the desinfection protocol in immature permanent teeth.

Our study demonstrates the superiority of new root canal systems in the disinfection of root canals in immature permanent teeth. The best results are demonstrated with the XP-Endo Finisher protocols with EDTA and citric acid (groups 4 and 5) and Gentlefile with citric acid (group 7). These root canal instruments were chosen because of the manufacturer's claims that they do not change the shape of the root canal and remove a minimal amount of dentin from the root walls (28-30).

The effectiveness of the XP-Endo Finisher system (groups 4 and 5) proven by our study is in accordance with results from other studies. In the study of Azim et al. XP-endo Finisher effectively reduced bacteria in the root canal (98.2\%), showing a statistically significant difference when compared to PIPS-erbium: yttrium aluminum garnet laser (89.6\%) and EndoActivator (93.3\%). The XP Endo finisher also has a high efficiency in killing bacteria in the dentin tubules and at 50 microns depth in the coronary, middle and apical thirds shows the highest percentage of killed bacteria - between $78 \%$ and $82 \%$. This may be due to the combination of the mechanical action of the file and the simultaneous activation of irrigation solutions, thereby facilitating the removal of microorganisms from the canal wall (31).

\section{Conclusion}

By supplementing the irrigation protocol with the use of the XP-Endo Finisher and Gentlefile Brush systems, a more efficient reduction of the microflora in the root canal is achieved without unnecessary dentin removal. The data show that this minimal mechanical scraping or brushing of the root canal with appropriate files significantly improves the removal of bacteria from the dentin surface and can be used as an alternative, effective and minimally invasive method of disinfection in regenerative endodontics. Our study demonstrated that the low-toxic citric acid improves the antibacterial action of chemical disinfection. Therefore, citric acid would be a useful supplement to the irrigation protocol, given its weaker proinflammatory action compared to EDTA-based solutions, as well as its important natural role in the tricarboxylic acid cycle, which is important for regulating energy homeostasis and cellular metabolism.

Acknowledgement: This work was supported by Medical University of Sofia, Grant №88/23.04.2019.

\section{References}

1. Mohammadi Z, Shalavi S, Jafarzadeh H. The oval shaped, root canal: A clinical review. S Afr Dent J 2015;70:200-204. 
2. Wu MK, van der Sluis LM, Wasselink PR. The capability of two hand instrumentation techniques to remove the inner layer of dentine in oval canals. Int Endod J 2003;36:218-224.

3. Weiger R, El Ayouti A, Lost C. Efficiency of hand and rotary instruments in shaping oval root canals. J Endod 2002;28:580-583.

4. Barbizam JV, Fariniuk LF, Marchesan MA et al. Effectiveness of manual and rotary instrumentation techniques for cleaning flattened root canals. J Endod 2002;28:365-366.

5. El Ayouti A, Chu AL, Kimionis I et al. Efficacy of rotary instruments with greater taper in preparing oval root canals. Int Endod J 2008;41:1088-1092.

6. Taha NA, Ozawa T, Messer HH. Comparison of three techniques for preparing oval-shaped root canals. J Endod 2010;36:532-535.

7. Hamood E. The Evaluation Of Success And Failure Of Endodontic Treatments. Australian Endodontic Journal. 2001;27:80-4.

8. Trope M, Debelian G. XP-3D Finisher ${ }^{\mathrm{TM}}$ file - the next step in restorative endodontics. Endodontic Practice US 2015;8(5):14-16.

9. Verma $\mathrm{P}$, Nosrat $\mathrm{A}$, Kim $\mathrm{J}$ et al. Effect of Residual Bacteria on the Outcome of Pulp Regeneration In Vivo. Journal of Dental Research 2016;96(1):100-106.

10. Narayanan LL, Vaishnavi C. Endodontic microbiology. J Conserv Dent 2010;13(4):233-239.

11. Distel J, Hatton J, Gillespie M. Biofilm formation in medicated root canals. J Endod 2002;28:689-693.

12. Zhang C, Du J, Peng Z. Correlation between Enterococcus faecalis and persistent intraradicular infection compared with primary intraradicular infection: a systematic review. J Endod 2015;41:1207-1213.

13. Pinheiro E, Gomes B, Ferraz C. Microorganisms from canals of root-filled teeth with periapical lesions. Int Endod J 2003;36:1-11.

14. Ring K, Murray $\mathrm{P}$, Namerow $\mathrm{K}$ et al. The comparison of the effect of endodontic irrigation on cell adherence to root canal dentin. J Endod 2008;34:1474-1479.

15. Casagrande L, Demarco FF, Zhang Z et al. Dentin-derived BMP-2 and odontoblast differentiation. J Dent Res 2010;89:603-608.

16. Fouad AF. The Microbial Challenge to Pulp Regeneration. Advanced Dentistry Research 2011;23(3):285-289.

17. Johnson WT, Noblett WC. Cleaning and Shaping in: Endodontics: Principles and Practice. Philadelphia, PA: Saunders 2009.

18. American Association of Endodontists. Clinical Considerations for a Regenerative Procedure [Internet]. Available

from: https://www.aae.org/uploadedfiles/publications and research/research/currentregenerativeen dodonticconsiderations.pdf.

19. Galler K, Krastl G, Simon S. European Society of Endodontology position statement: revitalization procedures. Int Endod J 2016;49:717-723.

20. van der Sluis $L$, Versluis $M$, Wu M. Passive ultrasonic irrigation of the root canal: a review of the literature. Int Endod J 2007;40:415-426.

21. Tran R, Wang L, Zhang $C$ et al. Synthesis and characterization of biomimetic citrate-based biodegradable composites. J Biomed Mater Res 2013;102:2521-2532.

22. Scelza Mea. Cytotoxic effects of $10 \%$ citric acid and EDTA-T used as root canal irrigants: an in vitro Analysis. J Endod 2001;27:741-743.

23. Malheiros C, Marques M, Gavini G. In vitro evaluation of the cytotoxic effects of acid solutions used as canal irrigants. J Endod 2005;31:746-748.

24. Scelza M, da Silva Pierro V, Chagas $M$ et al. Evaluation of Inflammatory Response of EDTA, EDTA-T, and Citric Acid in Animal Model. J Endod 2010;36:515-518.

25. Khedmat S, Shokouhinejad N. Comparison of the Efficacy of Three Chelating Agents in Smear Layer Removal. J Endod 2008;34:599-602.

26. Hu Y, Rawal A, Schmidt-Rohr K. Strongly bound citrate stabilizes the apatite nanocrystals in bone. P Natl Acad Sci 2010;107:22425-22429. 
27. Costello L, Franklin RB, Reynolds MA et al. The Important Role of Osteoblasts and Citrate Production in Bone Formation: "Osteoblast Citration" as a New Concept for an Old Relationship. Open Bone J 2012;4:27-34.

28. Trope M, Debelian G. Cleaning the third dimension. Endodontic Practice US 2015;8(6):22-24.

29. MedicNRG. Gentlefile2016. Available from: http://gentlefile.com/wpcontent/uploads/2016/07/the-finisher-GF-brush-kit-6.7.pdf.

30. Neelakantan P, Khan K, Li KY et al. Effectiveness of supplementary irrigant agitation with the Finisher GF Brush on the debridement of oval root canals instrumented with the Gentlefile or nickel titanium rotary instruments. Int Endod J 2018;51(7):800-807.

31. Azim A, Aksel H, Zhuang T et al. Efficacy of 4 Irrigation Protocols in Killing Bacteria Colonized in Dentinal Tubules Examined by a Novel Confocal Laser Scanning Microscope Analysis. J Endo 2016;42(6):928-934.

\section{Corresponding author:}

Krasimir Hristov,

Department of Pediatric Dentistry,

Faculty of Dental Medicine,

Medical University- Sofia,

1 Georgy Sofiyski Str.

tel: +359 883411743

email: khristov87@gmail.com 